\title{
Agrivoltaic system impacts on microclimate and yield of different crops within an organic crop rotation in a temperate climate
}

\author{
Axel Weselek ${ }^{1}$ (1) $\cdot$ Andrea Bauerle $^{2} \cdot$ Jens Hartung ${ }^{3} \cdot$ Sabine Zikeli ${ }^{4} \cdot$ Iris Lewandowski $^{2} \cdot$ Petra Högy $^{1}$
}

Accepted: 5 July 2021 / Published online: 20 August 2021

(C) The Author(s) 2021

\begin{abstract}
Agrivoltaic (AV) systems integrate the production of agricultural crops and electric power on the same land area through the installation of solar panels several meters above the soil surface. It has been demonstrated that $\mathrm{AV}$ can increase land productivity and contribute to the expansion of renewable energy production. Its utilization is expected to affect crop production by altering microclimatic conditions but has so far hardly been investigated. The present study aimed to determine for the first time how changes in microclimatic conditions through AV affect selected agricultural crops within an organic crop rotation. For this purpose, an AV research plant was installed near Lake Constance in south-west Germany in 2016. A field experiment was established with four crops (celeriac, winter wheat, potato and grass-clover) cultivated both underneath the AV system and on an adjacent reference site without solar panels. Microclimatic parameters, crop development and harvestable yields were monitored in 2017 and 2018. Overall, an alteration in microclimatic conditions and crop production under AV was confirmed. Photosynthetic active radiation was on average reduced by about $30 \%$ under AV. During summertime, soil temperature was decreased under AV in both years. Furthermore, reduced soil moisture and air temperatures as well as an altered rain distribution have been found under AV. In both years, plant height of all crops was increased under AV. In 2017 and 2018, yield ranges of the crops cultivated under AV compared to the reference site were -19 to $+3 \%$ for winter wheat, -20 to $+11 \%$ for potato and -8 to $-5 \%$ for grass-clover. In the hot, dry summer 2018, crop yields of winter wheat and potato were increased by AV by $2.7 \%$ and $11 \%$, respectively. These findings show that yield reductions under AV are likely, but under hot and dry weather conditions, growing conditions can become favorable.
\end{abstract}

Keywords Agrophotovoltaic $\cdot$ Agrivoltaic $\cdot$ Shading $\cdot$ Crop performance $\cdot$ Crop yield $\cdot$ Organic agriculture $\cdot$ Photovoltaics $\cdot$ Land productivity $\cdot$ Winter wheat $\cdot$ Potato $\cdot$ Grass-clover

\section{Introduction}

Agrivoltaic (AV) systems are currently discussed as an approach for the co-productive utilization of agricultural land

Axel Weselek

a.weselek@uni-hohenheim.de

1 Department of Plant Ecology and Ecotoxicology, Institute of Landscape and Plant Ecology, University of Hohenheim, Stuttgart, Germany

2 Department of Biobased Products and Energy Crops, Institute of Crop Science, University of Hohenheim, Stuttgart, Germany

3 Biostatistics Unit, Institute of Crop Science, University of Hohenheim, Stuttgart, Germany

4 Center for Organic Farming, University of Hohenheim, Stuttgart, Germany by combining food production and photovoltaic (PV) energy production on the same land area (Dinesh and Pearce 2016; Dupraz et al. 2011; Weselek et al. 2019). As the PV modules are raised several meters above the ground, agricultural production can be performed below the modules using standard land machinery. By further technical adaptations of the PV facility construction to the specific needs of crop cultivation, up to $60-70 \%$ of crop-available radiation can be maintained underneath the modules (Dupraz et al. 2011; Schindele et al. 2020; Trommsdorff et al. 2021; Weselek et al. 2021). At the same time, sufficient electrical yields can be achieved to increase both land productivity and farm income (Dinesh and Pearce 2016; Dupraz et al. 2011; Marrou et al. 2013c; Schindele et al. 2020; Trommsdorff et al. 2021). However, when evaluating the suitability of AV application in agricultural systems, its impact on microclimatic conditions and crop productivity is of major concern. To date, there are almost no 
references to microclimatic heterogeneities under $\mathrm{AV}$ in the scientific literature, and thus their impacts on crop yields remain uncertain (Weselek et al. 2019). So far, most studies dealing with AV systems have focused on simulations and modelling (Amaducci et al. 2018; Dinesh and Pearce 2016; Elamri et al. 2018; Homma et al. 2016), while actual data obtained from real field experiments is still scarce (Marrou et al. 2013a; Marrou et al. 2013b; Marrou et al. 2013c; Weselek et al. 2021; Weselek et al. 2019). In one of the very few studies based on a real field trial, several lettuce cultivars were grown under AV. Harvestable yields were virtually unaffected by $\mathrm{AV}$, depending on the cultivar and the spacing between the PV modules mounted above (Marrou et al. $2013 \mathrm{c}$ ). With a distance of $3.2 \mathrm{~m}$ between the solar panel rows, solar radiation was reduced by about 30\% (Marrou et al. 2013b; Marrou et al. 2013c). Water losses through evapotranspiration were decreased in the partial shade of the $\mathrm{AV}$ facility (Marrou et al. 2013a). However, besides solar radiation and soil temperature, which were decreased under AV, no significant differences were observed with regard to other microclimatic conditions, e.g. air temperature and humidity (Marrou et al. 2013b). Apart from crops like lettuce (Marrou et al. 2013c), corn (Sekiyama and Nagashima 2019) and horticultural crops like chiltepin pepper and cherry tomatoes (Barron-Gafford et al. 2019), the impacts of AV can only be taken from modelling studies (Amaducci et al. 2018; Homma et al. 2016). In simulations performed with a 40 -year climate dataset, Amaducci et al. (2018) found increased maize grain yields under AV in non-irrigated conditions. Under irrigated conditions, however, grain yields decreased. By contrast, Homma et al. (2016) predicted a $20 \%$ decrease in rice grain yields due to shading by $20 \%$. As a reduction in solar radiation is expected to be one of the most limiting factors for crop production under $\mathrm{AV}$, results can be transferred from experiments with cultivation in artificial (Dufour et al. 2013; Schulz et al. 2019) or natural shading conditions as occur for example in agroforestry systems (Artru et al. 2017). For winter wheat, grain yield reductions of up to $50 \%$ have been found, depending on shading intensity and point of time when shading was applied (Artru et al. 2017; Dufour et al. 2013). However, also, grain yields were increased in wheat under mild shading conditions as shown by Li et al. (2010). Comparable results have been observed for potatoes, where tuber number and total tuber yields were decreased with increased shading (Kuruppuarachchi 1990; Midmore et al. 1988; Sale 1973; Schulz et al. 2019). In regions with high solar radiation, however, shading was found to be beneficial for potato tuber yields when applied during specific stages of development or at specific times of the day (Kuruppuarachchi 1990; Midmore et al. 1988). For forage crops, yield responses to shading are more divergent with both yield reductions and increases being found, indicating the dependence on the studied species and climatic region (Pang et al. 2017).
As most of these studies apply shade using netting constructions, the transferability of the results to AV is limited, since shading patterns and microclimatic heterogeneities will differ (Weselek et al. 2019). Hence, to obtain solid data on the impacts of AV technology on crop production, field experiments are required. Accordingly, the aim of our study was to determine how microclimatic conditions and crop production are altered under an AV facility. To examine the technology under practical conditions, the study was performed on a commercial farm under organic management (Demeter certified). This farm was chosen, in particular, as organic farming in general strives for reducing external inputs and for an efficient and resource-conserving management (Weselek et al. 2021). In this context, AV seems to be an appropriate approach to improve electrical self-sufficiency and independency from fossil fuels.

\section{Material \& methods}

\subsection{Site description}

The research site $\left(47.85^{\circ}\right.$ latitude, $9.14^{\circ}$ longitude, approx. $660 \mathrm{~m}$ above sea level) is located on a field near Herdwangen-Schönach in south-west Germany in the region Lake Constance-Upper Swabia. Average annual air temperature is $8.7{ }^{\circ} \mathrm{C}$ and average annual rainfall $905 \mathrm{~mm}$ (climate data taken from the nearest weather station at Billafingen, less than $2 \mathrm{~km}$ away, $47.83^{\circ}$ latitude $9.13^{\circ}$ longitude, $537 \mathrm{~m}$ above sea level) (source: Agricultural Meteorology Baden-Wuerttemberg, published by the Agricultural Technology Centre Augustenberg (LTZ); accessible at www.wetter-bw.de).

The soil texture is classified as sandy loam. The AV facility extends from 656 to $667 \mathrm{~m}$ above sea level.

\subsection{AV plant}

The AV research plant was installed in August and September 2016 and has a total size of 0.3 ha and capacity of $194 \mathrm{kWp}$. In order to enable uniform light distribution for optimization of both PV and photosynthetic yield, the AV plant has been designed with several technical features (Fraunhofer ISE patent EP 2811819 B1; Trommsdorff et al. 2021). The facility is oriented in south-west direction. Bifacial solar panels with a row width of $3.4 \mathrm{~m}$ are installed on steel columns with a tilt angle of $20^{\circ}$ at a row distance of $6.3 \mathrm{~m}$ and a clearance height of $5 \mathrm{~m}$. Further technical details can be found in previous publications (Schindele et al. 2020; Trommsdorff et al. 2021; Weselek et al. 2019). 


\subsection{Setup and implementation of field experiment}

To assess the impacts of the AV system technology on crop performance and harvestable crop yield, four different crop species were selected as part of the farms common crop rotation (Fig. 1): winter wheat (Triticum aestivum var. "Elixer C", fodder wheat), potato (Solanum tuberosum var. "Regina"), grass-clover ("Siloprofi", 10\% Lolium perenne, 6\% Dactylis glomerata, $38 \%$ Phleum pratense, $12 \%$ Poa pratensis, $8 \%$ Festulolium, 5\% Medicago sativa, 9\% Trifolium pratense, $12 \%$ Trifolium repens) and celeriac. These crops were selected as they represent different types of crops: winter wheat and potatoes as two of the most relevant cash crops worldwide, celeriac as typical local vegetable and grass-clover as perennial forage crop and important element of organic crop rotations, which is cut several times a year. In addition, the selected crop species represent different plant physiological types for which different reactions to the cultivation under AV may be expected: winter crops (wheat), spring crops (celeriac and potatoes) and perennials (grass-clover). All crops were managed according to usual farm practice. Celeriac is not considered within the study as first results have recently been published by Weselek et al. (2021). Sowing, planting and harvest dates, along with other relevant agronomic measures, are provided in Table 1. The crops were grown in 19-m-wide strips. Each strip is subdivided into a plot under the AV system ("AV") and into a plot used as adjacent reference area ("REF") without solar panels on the same field. There was a distance of $20 \mathrm{~m}$ between the two plots to avoid shading of the reference area by the panels. Four $1-\mathrm{m}^{2}$ sampling areas were defined for each crop and treatment, resulting in a total of 24 sampling areas for data collection each year (Fig. 1a). The sampling areas beneath AV were each set in the middle of two panel rows, at a 4-m distance to the upper and downer edge of the growing strips (Fig. 1a, black lines) and a 5-m distance to the left and right edge of the AV facility to minimize border effects, particularly when solar altitude was low.

\subsection{Microclimate}

Measurements of microclimatic conditions included air humidity and temperature at a height of $2 \mathrm{~m}$ above the ground (VP-4 sensor), soil moisture and soil temperature approx. $25 \mathrm{~cm}$ below ground (5TM sensor) and photosynthetic active radiation (PAR; QSO-S sensor), estimated by photosynthetically active photon flux density. The values were logged in 30 -min intervals by 24 separate microclimate stations, each assigned to one of the sampling areas. The microclimate stations were placed in the non-processable area between the cropping strips on the same level as the steel columns of the AV facility (Fig. 1), to enable field processing with conventional land machinery without any restrictions. To provide homogenous light conditions underneath the facility, the AV construction has been designed according to preliminary simulation studies (Trommsdorff et al. 2021). Accordingly, the positioning of the QSO-S sensors recording PAR can be considered as representative for the whole facility. Soil sensors for the recording of soil moisture and temperature were placed next to the sampling areas (Fig. 1a, boxes) and only installed during the cropping season of each crop. All soil sensors were removed after final harvests of the crops to avoid any damage by tillage operations. Data loggers (EM50G) and all the sensors mentioned above were obtained from METER Group AG (Munich, Germany). For statistical analysis, the daily (24 h) values of each parameter and treatment were averaged. Rain distribution was recorded from June to October in 2017, and from July to October in 2018, using 28 rain gauges ( $70 \mathrm{~mm}$ volume; TFA Dostmann, Wertheim-Reicholzheim, Germany) mounted on wooden poles $2 \mathrm{~m}$ above the ground. Rain gauges were set up on the grass-clover cultivation area only, as this crop requires the fewest number of agronomic measures. Here, they were positioned in transect lines, each with seven gauges and two transects per treatment (AV/REF), to provide data for different areas underneath AV and on the REF site. The gauges were removed temporarily during the data acquisition period each year to allow agronomic measures to be carried out. Hence, the recorded precipitation does not match the actual rainfall amounts during this period. To compare the weather conditions, data on annual rainfall, solar radiation and temperature were taken from the weather station in Billafingen (see also Sect. 2.1).

\subsection{Monitoring and harvest of crops}

Monitoring of crop performance and crop yields was carried out over two growing seasons from December 2016 until October 2018. No monitoring was carried out between November 2017 and April 2018 due to unfavorable weather conditions. During this period, the soil was either so wet that it was impossible to access the field without damaging the crops or the field site was covered with snow. However, due to low temperatures, crop growth can be regarded to be virtually zero during that time.

Crop development was monitored every fourth week and from flowering onwards every second week. On each of the wheat and potato plots, ten single plants were selected and tagged for monitoring. For a better comparison between the 2 years, the results are presented with days after sowing (DAS) for wheat, day of year (DOY, with January $1^{\text {st }}$ defined as 1 DOY) for grass-clover and days after planting (DAP) for potato. Monitoring included non-destructive measurements of plant height (using a folding ruler) and growth stage (BBCH scale) of the tagged plants. Non-destructive measures were taken from each plant and averaged across plants within each sampling area. Leaf area index (LAI; LAI-2200C Plant Canopy Analyzer, LI-COR Biosciences, Lincoln, USA) was 


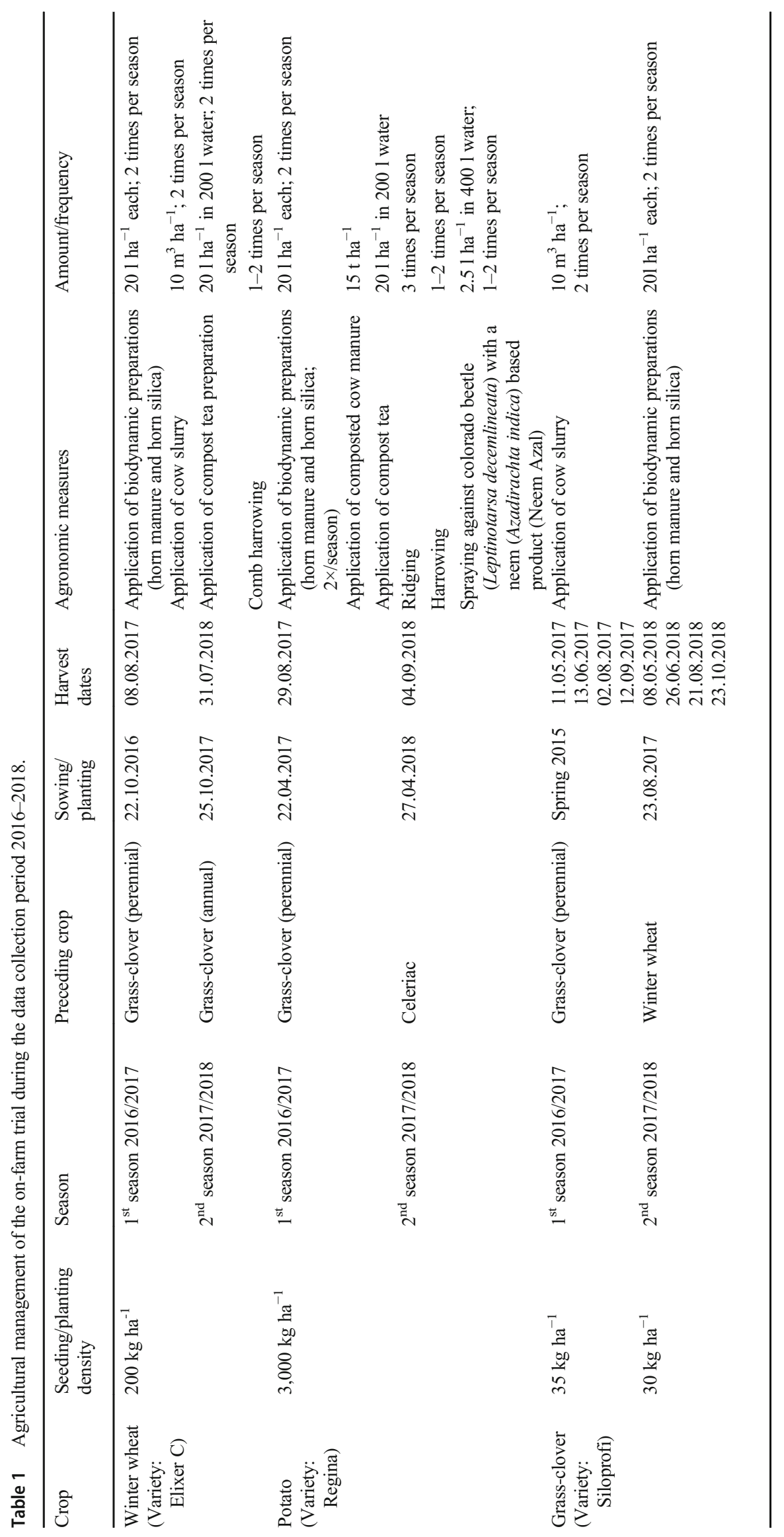




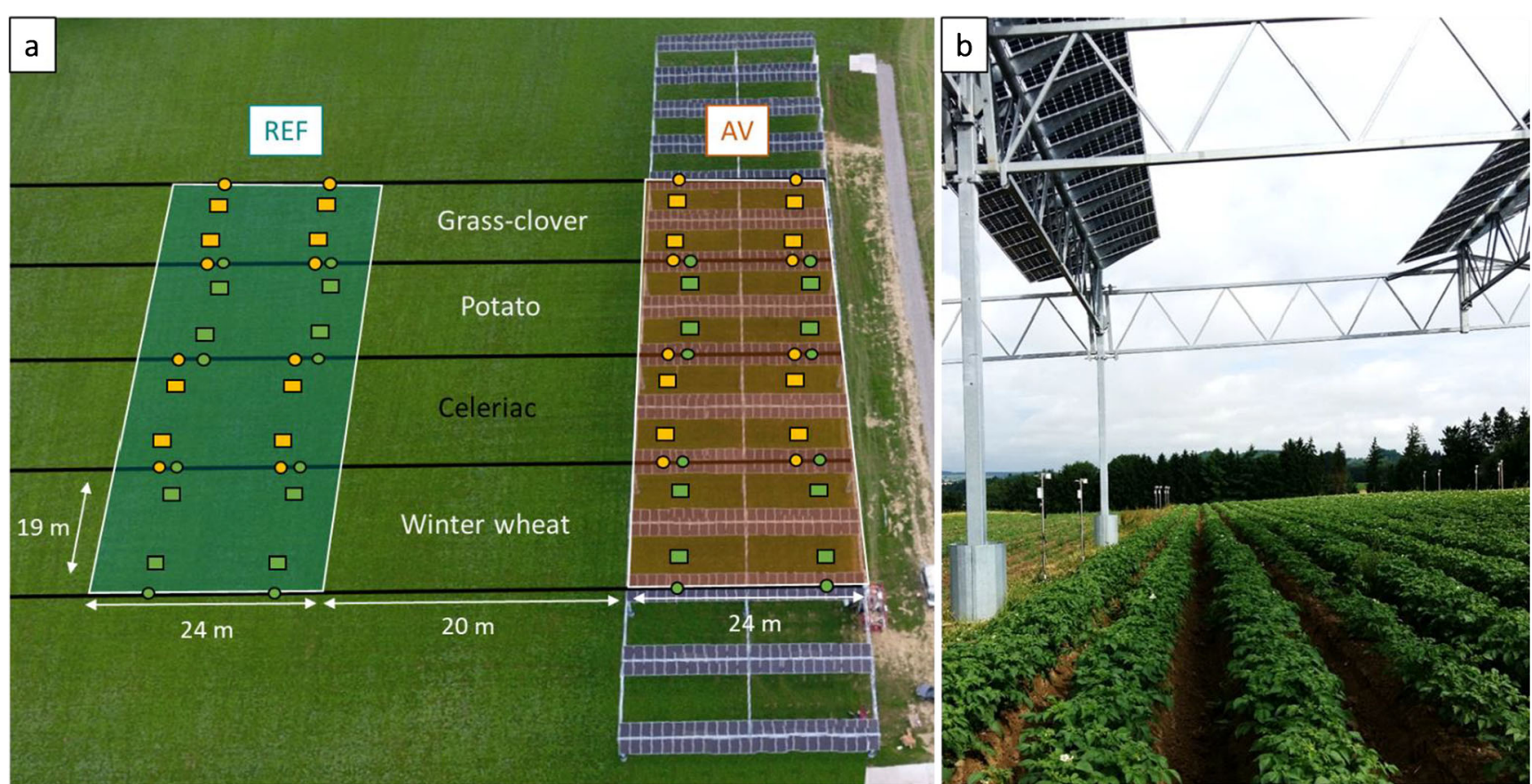

Fig. 1 Field trial design of the first cropping season 2017 with reference (REF) and agrivoltaic (AV) sites (a). Crops are grown in strips. Sampling areas are indicated by boxes, positions of microclimate stations by circles. Soil sensors were placed next to the sampling areas. Celeriac was part of the crop rotation but is not considered within this study. (b): Potatoes

measured at four different positions of each sampling area and averaged for each area. The measurements were taking in exactly the same way in the grass-clover plots, but without tagging individual plants. Here, crop height was estimated at ten random positions within the sampling areas. In addition, the proportions of grass and clover were determined by estimating surface coverage ratio.

Each sampling area was harvested manually immediately before the farm's usual harvest dates. Wheat was harvested at maturity, and the aboveground biomass was separated into stems, leaves and ears. Dry weight was determined after drying for $48 \mathrm{~h}$ at $30^{\circ} \mathrm{C}$ (ears) or $60{ }^{\circ} \mathrm{C}$ (leaves and stems). Ears were threshed to determine the grain yield. Thousand grain weight was determined using a seed counter (Contador, Pfeuffer GmbH, Kitzingen, Germany). For the estimation of grain size classes $(<1.8 \mathrm{~mm}$; $1.8-2.0 ; 2.0-2.2 ; 2.2-2.5 ; 2.5-2.8 ;>2.8), 100 \mathrm{~g}$ grains were sorted (Sortimat K5, Pfeuffer GmbH, Kitzingen, Germany) and weighed back to estimate the share of each class. Potatoes were washed and sorted according to diameter $(<35 \mathrm{~mm}, 35-50 \mathrm{~mm}$, $>50 \mathrm{~mm}$ ) before determining the fresh weight. Grass-clover was cut four times per year, and dry matter yield was determined by drying the biomass at $60{ }^{\circ} \mathrm{C}$ to constant weight.

\subsection{Statistical analysis}

The experimental setup can be considered as a single replicate of a strip-plot design where treatment (AV and REF) and crop growing under the AV panels (front) and on the REF site (back). Microclimatic stations have been placed in line with steel columns of the facility. (Source: (a) modified after BayWa r.e; (b) Bauerle/ University of Hohenheim).

rotation were allocated to columns and rows, respectively. A plot (a combination of treatment and crop rotation) was further divided into two lanes with two measurements taken per lane (resulting in four sampling areas per plot and two per lane, respectively). Lanes were created by the working widths and the working direction of the machinery for processed in cropspecific working steps and coded as south and north. Repeated measures were taken on each plot. Note that a true replicate for treatment would require another AV system. The data analysis for traits of crop development was carried out with SAS software version 9.3 (SAS Institute Inc., Cary, NC, USA) using the following model:

$y_{i j k l}=\mu+b_{k i j}+\tau_{i}+\varphi_{j}+(\tau \varphi)_{i j}+e_{i j k l}$,

where $b_{k i j}$ is the fixed effect of lane $k$ in treatment $i$ at day $j$, $\tau_{i}$ is the $i$-th treatment effect, $\varphi_{j}$ is the $j$-th day effect and $(\tau \varphi)_{i j}$ is the interaction effect of day $j$ and treatment $i . e_{i j k l}$ is the repeated measurement error of observation $y_{i j k l}$ with a firstorder autoregressive variance-covariance structure of error effects from the same measuring point. Note that the variance of repeated measures on the same plot under-estimates the true error variance, and thus, all tests are too liberal. Further note that the considered traits are crop-specific; thus, analysis was performed for each crop separately.

As harvestable crop yield was measured in two successive years but only once per year, an analogous model to (1) can be fitted replacing day $j$ with year $n$ : 
$y_{\text {inkl }}=\mu+b_{\text {kin }}+\tau_{i}+\rho_{n}+(\tau \rho)_{i n}+e_{i n k l}$,

where $\rho_{n}$ and $(\tau \rho)_{i n}$ are the effects of the $n$-th year and its interaction effects with treatment. All other effects are defined analogous to model (1).

The microclimate data were evaluated in all crops. Thus, another linear mixed model was used:

$$
\begin{aligned}
y_{i j k l m}= & \mu+b_{k i j n}+\tau_{i}+\varphi_{j}+\vartheta_{m}+(\tau \varphi)_{i j}+(\tau \vartheta)_{i m} \\
& +(\varphi \vartheta)_{j m}+(\tau \varphi \vartheta)_{i j m}+e_{i j k l m},
\end{aligned}
$$

where $\vartheta_{m}$ is the effect of the $m$-th crop and $(\tau \vartheta)_{i m},(\varphi \vartheta)_{j m}$ and $(\tau \varphi \vartheta)_{i j m}$ are the corresponding interaction effects with the $m$-th crop. Residuals were checked graphically for homogeneous variances and normal distribution. After finding significant differences via $\mathrm{F}$ test, a multiple $t$ test (Fisher's LSD test) was performed. Results of multiple $t$ tests were presented as a letter display. Note that care should be taken with the interpretation of letter displays as these tests are too liberal.

\section{Results and discussion}

\subsection{Microclimate}

No microclimate data could be recorded from 11 October until 23 November in 2017 and from 11 until 14 December in 2018 for technical reasons. Therefore, yearly mean values have been taken from the weather station in Billafingen: The weather conditions in the years were quite different with an extraordinary dry and hot summer in 2018. In 2017, accumulated precipitation was $1351 \mathrm{~mm}$, annual solar radiation $1180 \mathrm{kWh} / \mathrm{m}^{2}$ and mean temperature $8.6^{\circ} \mathrm{C}$; in 2018 , they were $916 \mathrm{~mm}$, $1204 \mathrm{kWh} / \mathrm{m}^{2}$ and $9.7^{\circ} \mathrm{C}$, respectively (source: weather station Billafingen). In 2018 , the $1.1^{\circ} \mathrm{C}$ higher average annual temperature compared to 2017 was mainly due to increased air temperatures during summertime: From July to September, monthly average temperature was on average $2{ }^{\circ} \mathrm{C}$ higher in 2018 compared to 2017 . The mean daily PAR was significantly reduced $(p<0.05)$ by about $30 \%$ underneath AV in both $2017(n=359$ days $)$ and $2018(n=363)$, with only slight variations between months (Fig. 2a). In 2017, daily mean PAR on the REF site was highest on 11 June at $678.9 \mu \mathrm{mol}$ $\mathrm{m}^{-2} \mathrm{~s}^{-1}$ and lowest on 10 December at only $19.9 \mu \mathrm{mol} \mathrm{m}^{-2} \mathrm{~s}^{-1}$. Interestingly, the dates with maximum and minimum values were slightly different on the AV site at $480.9 \mu \mathrm{mol} \mathrm{m}^{-2} \mathrm{~s}^{-1}$ on the 10 June and $14.4 \mu \mathrm{mol} \mathrm{m}^{-2} \mathrm{~s}^{-1}$ on 25 November. In 2018, daily mean PAR was highest on 20 June at $683.7 \mu \mathrm{mol} \mathrm{m}^{-2} \mathrm{~s}^{-1}$ (REF) and $471.8 \mu \mathrm{mol} \mathrm{m}^{-2} \mathrm{~s}^{-1}$ (AV), and lowest on 4 January at $15.8 \mu \mathrm{mol} \mathrm{m}^{-2} \mathrm{~s}^{-1}$ (REF) and $6.7 \mu \mathrm{mol} \mathrm{m}^{-2} \mathrm{~s}^{-1}$ (AV) on 10 December. These findings are comparable with results from previous AV experiments, in which predicted and measured light reductions ranged from 12 to $40 \%$, depending on the density and orientation of the PV modules mounted above (Amaducci et al. 2018; Majumdar and Pasqualetti 2018; Marrou et al. 2013b; Weselek et al. 2019). With on average $70 \%$ available PAR underneath the AV facility in Heggelbach, even more radiation was available than predicted in preliminary simulations (Trommsdorff et al. 2021).

Soil moisture was significantly decreased under AV on 26 days in 2017 and on 133 days in 2018. In 2017, significant differences only occurred during wintertime from the end of November onwards. Similar results were observed in 2018, where daily mean soil moisture was significantly lower under AV until the middle of April and from the end of October onwards. This result is surprising since soil moisture was expected to be higher under AV during summertime due to lower evapotranspiration (Amaducci et al. 2018; Marrou et al. 2013a). However, the studies by Amaducci et al. (2018) and Marrou et al. (2013a) were performed in irrigated systems with spring crops like maize, lettuce and cucumber, and therefore the results are difficult to compare with ours. Furthermore, the results of the rain distribution measurements (see next section) indicated that the plots were placed in the rain-sheltered area of the facility between the panel rows, corresponding to rain gauge positions $\mathrm{P} 3$ and P5 (Fig. 2b).

Mean daily soil temperature under AV was on average about $1.2{ }^{\circ} \mathrm{C}$ lower in $2017(n=201 ; p<0.05)$ and $1.4{ }^{\circ} \mathrm{C}$ lower in $2018(n=205 ; p<0.05)$ on almost every day from the beginning of March to the middle of October (Fig. 2c). Also, Marrou et al. (2013b) found reduced soil temperatures under $\mathrm{AV}$, ranging from $-0.5^{\circ} \mathrm{C}$ in irrigated lettuce to $-2.3{ }^{\circ} \mathrm{C}$ and $-1.9^{\circ} \mathrm{C}$ in wheat at $25-\mathrm{cm}$ and $5-\mathrm{cm}$ depth, respectively. In addition to crop-related variations and depths, soil temperature was also affected by the density of the modules mounted above: Increased module density led to lower temperatures, except in wheat at 25-cm depth (Marrou et al. 2013b). Our results further indicated that the soil underneath $\mathrm{AV}$ is heating up more slowly and less strong compared to open field conditions. This may be advantageous during summertime but can also become adverse, especially in spring when quick soil heating is demanded in terms of nitrogen mineralization.

In both, 2017 ( $n=132$ days) and $2018(n=112$ days) daily mean air temperature was significantly lower by about $1.1^{\circ} \mathrm{C}$ on average. This effect was found across the whole year but was most prevalent during summertime. However, on 7 days in 2017 and 18 days in 2018, measured air temperature was higher under AV. In contrast, Marrou et al. (2013b) found that air temperature tended to be higher underneath the AV facility on days with high solar radiation or low wind speeds. In our field trial, wind speeds have not been assessed. However, as the study of Marrou et al. (2013b) has been performed under different conditions (e.g. climatic region, design of the AV facility, crop selection and irrigation), multiple explanations for the opposing results are conceivable. 


\section{a Photosynthetic photon flux density [ $\mu \mathrm{mol} \mathrm{m} \mathrm{m}^{-2} \mathrm{~s}^{-1}$ ]}

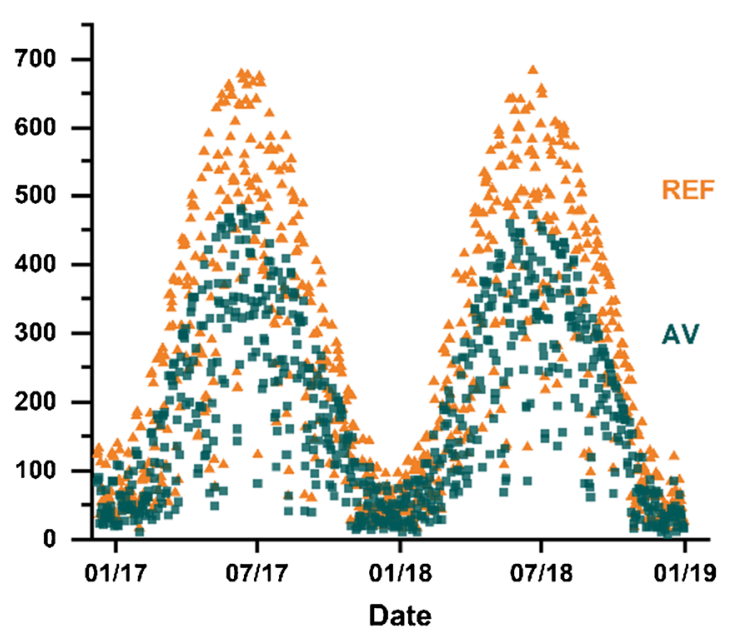

C Daily mean soil temperature
$\left[1 \mathrm{~m}^{-2}\right.$ cumulated]

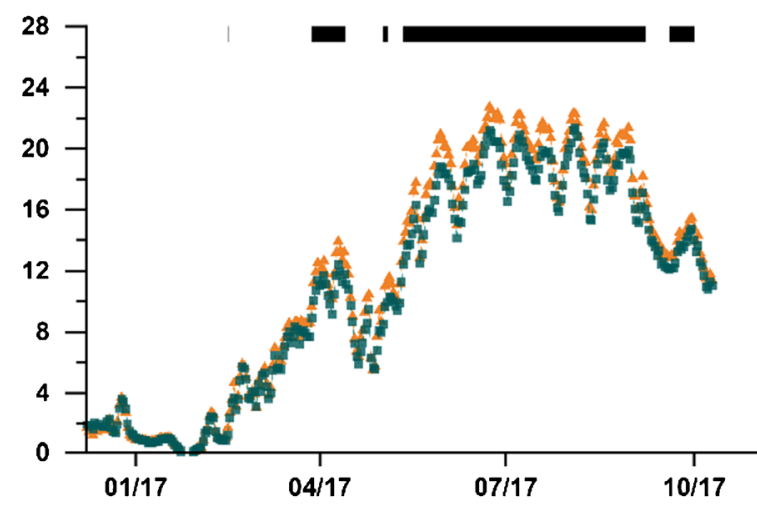

Fig. 2 (a) Daily means of photosynthetic active radiation (PAR) in 2017 and 2018 underneath agrivoltaic (AV, cyan squares) and on the reference site (REF, orange triangles). (b) Rainfall distribution underneath the AV panels (cyan bars) and on REF (orange bars) in 2017 (non-hatched) and 2018 (hatched bars). Error bars indicate standard deviation. Harvest and
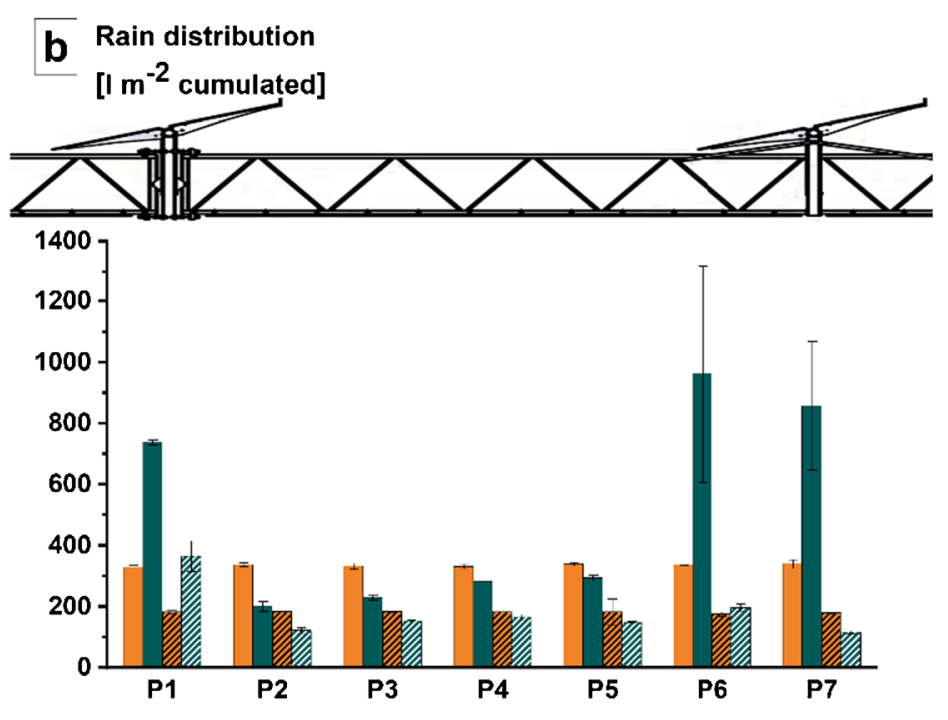

Rain gauge position

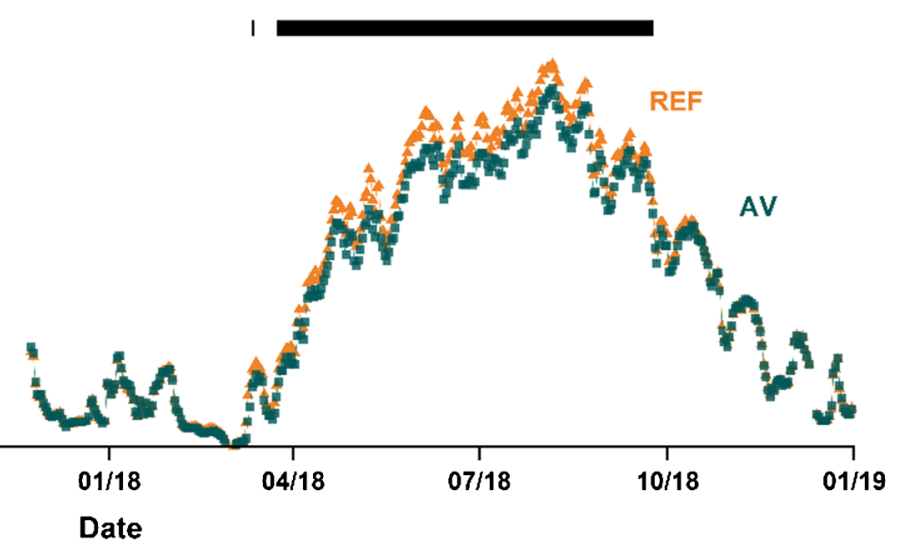

monitoring plots of the crops were placed between rain gauge positions P3 and P5. (c) Daily mean soil temperature in both years for AV (cyan squares) and REF (orange triangles). Significant differences $(p<0.05)$ between AV and REF in (c) are indicated by black horizontal bars.

In both years, air humidity was higher under AV on several days. In 2017 , daily mean air humidity was on average $2 \%$ higher on 60 days and $2 \%$ higher on 44 days in 2018 under $\mathrm{AV}$, respectively. The differences mainly occurred in wintertime from October onwards in 2017 and before April in 2018.

The accumulated precipitation was $439 \mathrm{~mm}$ lower in 2018 (912 mm) than in 2017 (1351 mm; source: weather station Billafingen), in particular due to low precipitation during summer (Weselek et al. 2021). As described in Sect. 2.4., in our trial, rain gauges had to be removed occasionally when agronomic measures were carried out. Therefore, the collected amounts in our field trial do not reflect the actual precipitation for that period. Consequently, the average accumulated precipitation of the rain gauges recorded in our trial was only
$335 \mathrm{~mm}$ in 2017 and $181 \mathrm{~mm}$ in 2018 (Fig. 2c: a-g), while the accumulated precipitation at the weather station Billafingen for the same period (see also Sect. 2.4) was $771 \mathrm{~mm}$ in 2017 and $190 \mathrm{~mm}$ in 2018. However, as the Billafingen weather station is located almost $2 \mathrm{~km}$ away at a much lower sea level and rainfall events can be locally quite different due to a hilly landscape, measured rainfall amounts are not totally suitable for comparison. The local microclimates can be expected to be slightly different.

In addition, precipitation was unequally distributed underneath the AV facility. For example, in 2017, the average cumulated amount of rainfall collected at rain gauge positions "P2" and "P3" on the AV site was only $215 \mathrm{~mm}$, whereas it was $335 \mathrm{~mm}$ on the REF site (Fig. 2b). The amounts collected 
by the gauges at positions "P1", "P6" and "P7" in the same period were $738 \mathrm{~mm}, 964 \mathrm{~mm}$ and $857 \mathrm{~mm}$, respectively. The PV panels are divided into two parts: position "P1" and "P7" are under to the draining edge of the first panel, and position "P6" to that of the second panel. Consequently, a rain sheltering effect occurred in the areas between two panel rows ("P2"-"P5"), while directly underneath the panels, rain concentration effects led to increased amounts of water being collected in the rain gauges under the panel edges. However, as the high standard deviation at positions "P6" and "P7" in 2017 and less distinct results for 2018 indicate, the runoff from the panel edges is limited to a very small area and slight variations in rain gauge positions already led to deviating results. For this reason and due to low precipitation in general, differences between the rain gauge positions under the AV facility were less pronounced in 2018. Elamri et al. (2018) reported similar results, with rain to be distributed unequally underneath an AV system. As they have shown, such heterogeneities depend on the direction of the PV panels and may even be avoided in systems with mobile PV modules and time-dependent adjusting of panel tilt angles (Elamri et al. 2018).

As the sensors recording soil temperature and moisture have been placed at positions underneath the AV facility which are corresponding to rain gauge positions "P4" and "P5", further measurements are needed to investigate whether found alterations in soil microclimate are representative for the whole area underneath the AV plant. The slight slope of the experimental site in both a north-west and south-west direction will also affect water redistribution in the soil after rainfalls. In 2017, drainage gullies were observed after heavy rainfalls in the potato field directly underneath the panel edges of the AV facility. Consequently, an increased risk of soil erosion under AV can be assumed in particular in early stages of crop development with virtually bare soils.

As shown, microclimate was affected by AV in several ways. PAR, soil temperature and moisture, as well as air temperature, were significantly reduced under the AV facility, whereas air humidity partly increased. PAR was on average reduced by about $30 \%$ under $\mathrm{AV}$ and, hence, is considered to be the most relevant constraint for crop production. However, the results have also shown that alterations in microclimate and between the treatments are also affected by the crop cultivated underneath. As shown for celeriac, mean soil moisture on average increased under AV during celeriac vegetation period in 2017 (Weselek et al. 2021), which seems contradictory to the results of daily means, but may explain found differences between winter and summertime. Therefore, a more in-depth analysis of microclimatic data, also addressing spatial, temporal and crop-related differences is needed, to fully understand microclimatic alterations under AV. In this context, a high-resolution acquisition of microclimatic data, covering representing areas underneath the AV facility, is required to assess microclimatic heterogeneities. As the measurements of rain distribution indicated, precipitation is distributed unevenly under $\mathrm{AV}$, and hence, also the technical design of prospective AV facility should be improved to ensure a more even rain distribution. Besides variations between the treatments, climatic conditions were quite different in the years 2017 and 2018, with low precipitation and high temperatures especially during summer 2018.

\subsection{Crop development}

Canopy height of winter wheat was significantly higher under AV than in REF from 201 DAS onwards in $2017(+8.2-$ $19.9 \%)$ and from 195 DAS onwards in $2018(+16.4-19.1 \%)$ until final harvest (Fig. 3). This confirms earlier findings by McMaster et al. (1987), who also found increased winter wheat canopy height under shading. LAI of the wheat canopy was significantly higher under AV on one monitoring date (262 DAS; $+24.5 \%$ ) in 2017 and on four monitoring dates in 2018 (195, 232, 244 and 272 DAS; +23-35.9\%; data not shown). Comparable results have been found by $\mathrm{Li}$ et al. (2010) and can be explained as morpho-physiological response of wheat plants in order to capture more light and compensate for reduced light incidence ( $\mathrm{Li}$ et al. 2010). In contrast, no significant effects of shading on the LAI dynamics of winter wheat were found in agroforestry experiments (Artru et al. 2017; Dufour et al. 2013). However, in these experiments, shading was applied at late stages of development at which vegetative growth was almost completed (Artru et al. 2017). In 2017, no significant differences in growth stage were observed between the two treatments, although senescence had progressed further on the REF site at 262 DAS. In 2018 , winter wheat was at a higher growth stage on the REF site than on the AV site at 232 and 244 DAS. This was clearly visible from the color of the crop canopy, which was still green under AV but already turning yellow on the REF site. Comparable results were described by Marrou et al. (2013b), who found crop development of wheat to be slightly delayed in the shade of PV modules. This may be explained by differences in the photothermal ratio between the two treatments leading to a delay in maturation under AV (Fischer 1985). However, in our trial, all visible differences had vanished by harvest.

Comparable results were found in potatoes, where canopy height was significantly higher under AV on several monitoring dates in 2017 (66 and 80 DAP; +12.4-19.3\%) and 2018 (48, 60 and 74 DAP; +5.1-15.9\%) (Fig. 3). This is in agreement with LAI, which was significantly higher under AV at two monitoring days in 2017 (80 and 102 DAP; +28.5$53.4 \%$ ) and two in 2018 (60 and 74 DAP; +14.6-20\%) (data not shown). At one monitoring date in 2017, LAI was lower under AV (66 DAP; -24.5\%). These findings are in agreement with Kuruppuarachchi (1990) who found increased 
Fig. 3 Plant height of winter wheat (left) and potato (right) in 2017 and 2018 underneath agrivoltaic (AV, cyan squares) and on the reference site (REF, orange triangles). Significant differences $(p<0.05)$ are indicated by stars, standard deviation by error bars.

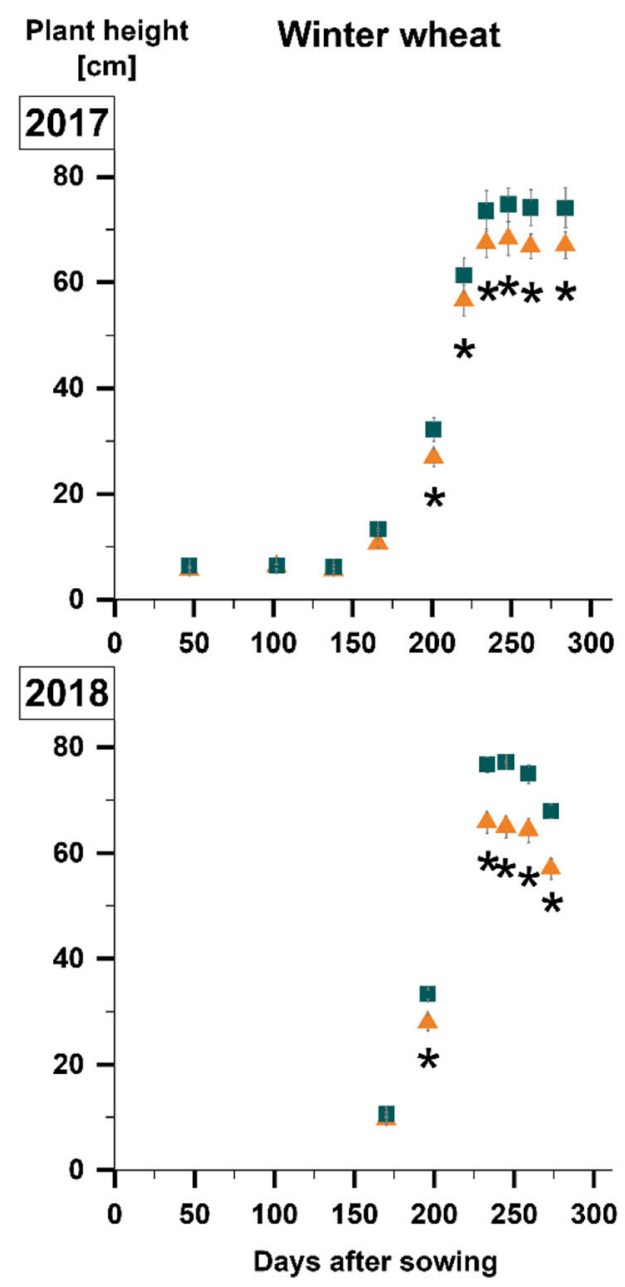

Plant height [cm]
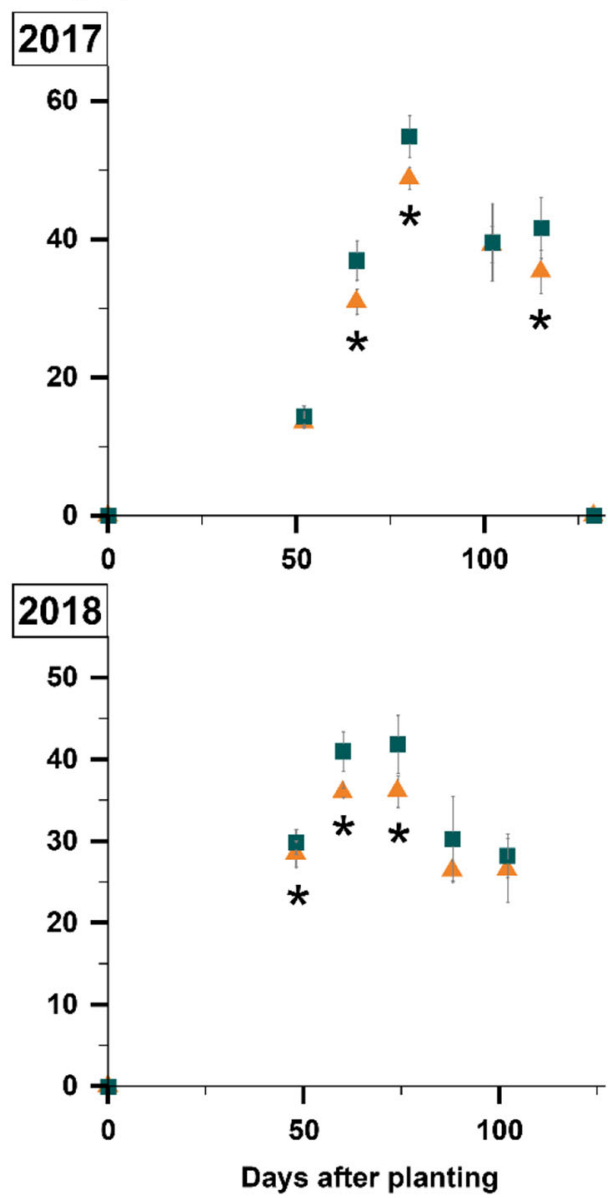

canopy height of potatoes under artificial shading. Besides canopy height and LAI, growth stages were also affected by $\mathrm{AV}$ in our experiment. In both years, flowering tended to start earlier on the REF site. In 2018, leaf senescence of potato plants started later under AV than on the REF site. At final harvest, however, differences in growth stages and tuber ripeness were no more visible. In 2017, no significant differences in growth stages were observed between the treatments.

In grass-clover, canopy height and LAI also differed significantly between AV and REF on several days in both 2017 and 2018 (Fig. 4). Apart from few exceptions shortly after the plots were cut, canopy height and LAI were always higher on AV than in REF. In addition, a trend of faster regrowth after cutting was observed on AV plots. This was particularly visible after the $3^{\text {rd }}$ and $4^{\text {th }}$ cut in 2017 (226 DOY and from 268 DOY onwards). The assumption that this was due to better water supply under $\mathrm{AV}$ was not confirmed as soil moisture actually tended to be lower under AV (see also Sect. 3.1). However, these findings may also be explained by species-specific growth differences. As the estimation of clover:grass ratio revealed, the average proportion of clover on the AV site was 62\% in 2017 and $49 \%$ in 2018, compared to $57 \%$ and $45 \%$ on the REF site. Therefore, observed differences in canopy height and growth between the two treatments may be explained by deviating species proportions. In a comprehensive screening for shade adaptability of different forages, Pang et al. (2017) showed that some species (e.g. white clover) can be favored by shading. As these findings also affect biomass yields, they are discussed in more detail in Sect. 3.3.

Monitoring of crop development revealed that canopy height and LAI of winter wheat, potatoes and grass-clover increased under AV. Comparable results have been found for celeriac, where both LAI and crop height were significantly increased by AV (Weselek et al. 2021). The results may be explained as shade-adaptive response to increase light capture by increased vegetative growth, in order to compensate for reduced radiation in the shade of the AV panels. Furthermore, crop development was slightly delayed by $\mathrm{AV}$, but all visible interim differences had disappeared at final harvest.

\subsection{Harvestable crop yields}

Differences in harvestable crop yields of winter wheat were found both, between treatments (AV and REF) and years (2017 and 2018) (Fig. 5a). Harvest index was significantly lower 
Fig. 4 Plant height (left) and leaf area index (right) of grass-clover in 2017 and 2018 underneath agrivoltaic (AV, cyan squares) and on the reference site (REF, orange triangles). Significant differences $(p<0.05)$ are indicated by stars, standard deviations by error bars.
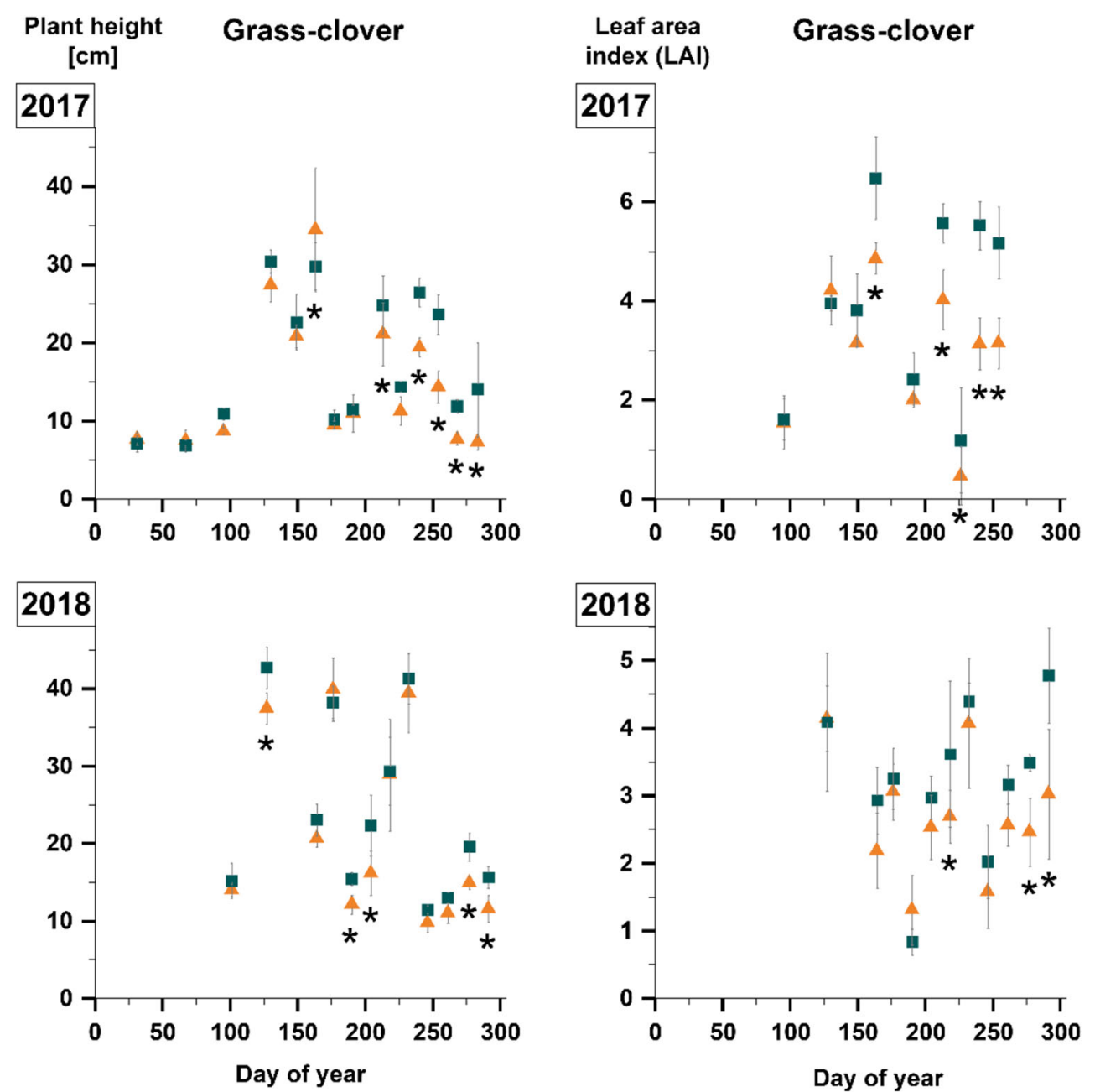

under AV in both years, with 57. 2 (AV) compared to 59.8 (REF) in $2017(p=0.008)$, and 56.1 (AV) compared to 59.3 $(\mathrm{REF})$ in $2018(p=0.002)$. Straw yield was $2.9 \mathrm{tha}^{-1}(\mathrm{REF})$ and $2.6 \mathrm{t} \mathrm{ha}^{-1}$ (AV) in 2017 (-7.1\%; not significant), and $2.2 \mathrm{tha}^{-1}$ (REF) and $2.7 \mathrm{t} \mathrm{ha}^{-1}$ (AV) in 2018 (+22.1\%; not significant). In 2017, higher straw yield in REF was mainly due to higher stalk weight (not significant). In 2018, both stalk (not significant) and leaf weight $(p=0.004)$ were higher under AV. In 2017, grain yield of winter wheat was $4.6 \mathrm{tha}^{-1}$ under AV compared to $5.7 \mathrm{t}$ $\mathrm{ha}^{-1}$ on the REF site $(-18.7 \% ; p=0.03)$. In 2018 , it was $4.7 \mathrm{t}$ $\mathrm{ha}^{-1}$ under AV compared to $4.6 \mathrm{t} \mathrm{ha}^{-1}$ in REF $(+2.7 \%$; not significant; $p=0.78$ ). Grain yield of both AV and REF was significantly lower in 2018 compared to REF yields in 2017. In a study by Li et al. (2010), changes in grain yields ranged from $+1.8 \%$ for a shade-adapted cultivar under $8 \%$ shade up to $-7.2 \%$ for a shade-sensitive cultivar under $23 \%$ shade. In contrast, Dufour et al. (2013) found a reduction in grain yields as high as $50 \%$ under $31 \%$ shading due to a decline in both number of grains per ear and grain weight. The results show that the reduction in grain yields of winter wheat under shading is most likely due to decreased single grain weights, while its extent appears to depend very much on cultivar and climatic conditions. Under certain conditions, even increased grain yields are possible as shown by Li et al. (2010). Our results from 2018 in particular indicate that under hot and dry conditions, reduced sunlight will most probably not be a limiting factor for yield levels. Beside grain yields, also grain size distribution was affected. While in 2017, 89\% (REF) and 88\% (AV) of grains were bigger than 2.8 $\mathrm{mm}$, in 2018 only $75 \%$ (REF) and 53\% (AV) of grains were bigger than $2.8 \mathrm{~mm}(p<0.0001)$. Accordingly, the share of smaller grain size classes was higher under AV in 2018: Grains with a size of 2.5-2.8 mm had a share of $18 \%$ (REF) and $34 \%$ (AV) ( $p$ $<0.0001$ ), and grains with a size of $2.2-2.5 \mathrm{~mm}$ a share of $6 \%$ (REF) and $11 \%(\mathrm{AV})(p<0.0001)$. In both, $2017(p=0.03)$ and 2018 ( $p=0.0002)$, thousand grain weight was significantly lower under AV. Reductions in harvest index and thousand grain weight have also been found in shading experiments of Artru et al. (2017). In our study, lower harvest index under AV most probably can be explained by lower grain yields in 2017, and increased straw yields in 2018, compared to the REF site 

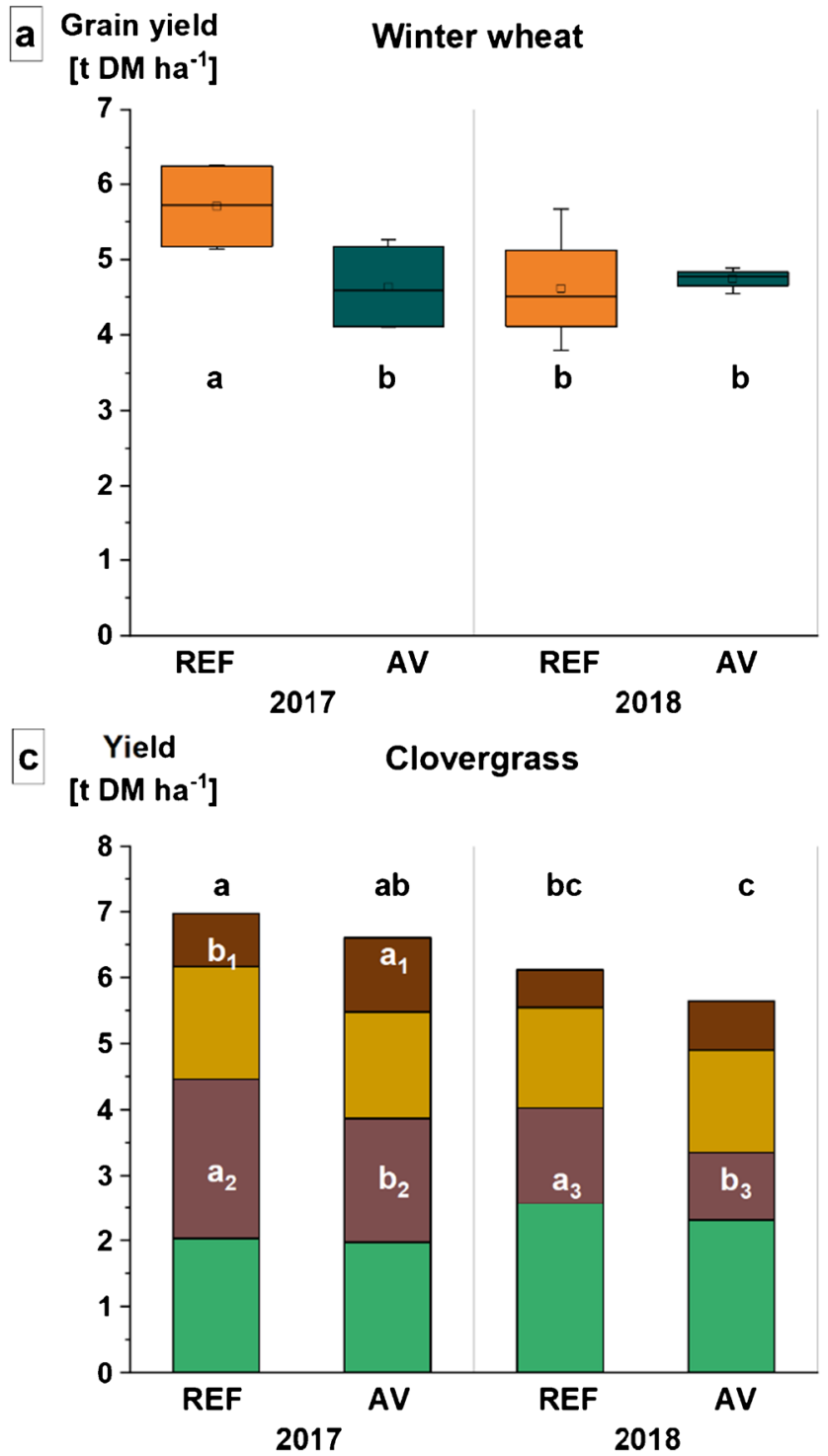

Fig. 5 Yields of winter wheat (a), potato (b) and grass-clover (c), as well as tuber size fractionation of potato (d) in the years 2017 and $2018(\mathrm{DM}=$ dry matter; FM = fresh matter). Different letters indicate significant differences between reference (REF) and agrivoltaic (AV), with $a>b$ $(p<0.05)$. Whisker boxplots $(25-75 \%)$ with whisker length of 1.5

respectively. Increases in straw biomass can be explained by a higher crop canopy and LAI in 2018 (see also Sect. 3.2.).

In 2017, the reduction of potato tuber yield under AV in 2017 was comparable to the reduction of grain yield of winter wheat. Fresh matter (FM) tuber yield was $23.6 \mathrm{t} \mathrm{ha}^{-1}$ for $\mathrm{AV}$ and $28.8 \mathrm{t}$ $\mathrm{ha}^{-1}$ for REF in $2017(-18.2 \% ; p=0.005)$, and $25.5 \mathrm{tha}^{-1}$ (AV) and $23.0 \mathrm{t} \mathrm{ha}^{-1}$ (REF) in $2018(+11 \%$; $p=0.034)$ (Fig. 5b). Average tuber yields of potatoes grown organically in Germany were on average $22.0 \mathrm{t} \mathrm{ha}^{-1}$ in 2017 and $25.0 \mathrm{tha}^{-1}$ in 2018. Thus, tuber yields in our trial from both years and treatments were comparable to the national average. The proportion of large potato tubers ( $>50 \mathrm{~mm}$ ) was higher on the REF site in 2017 ( $p=0.012$ ) and 2018 (not significant; $p=0.052$ ), while

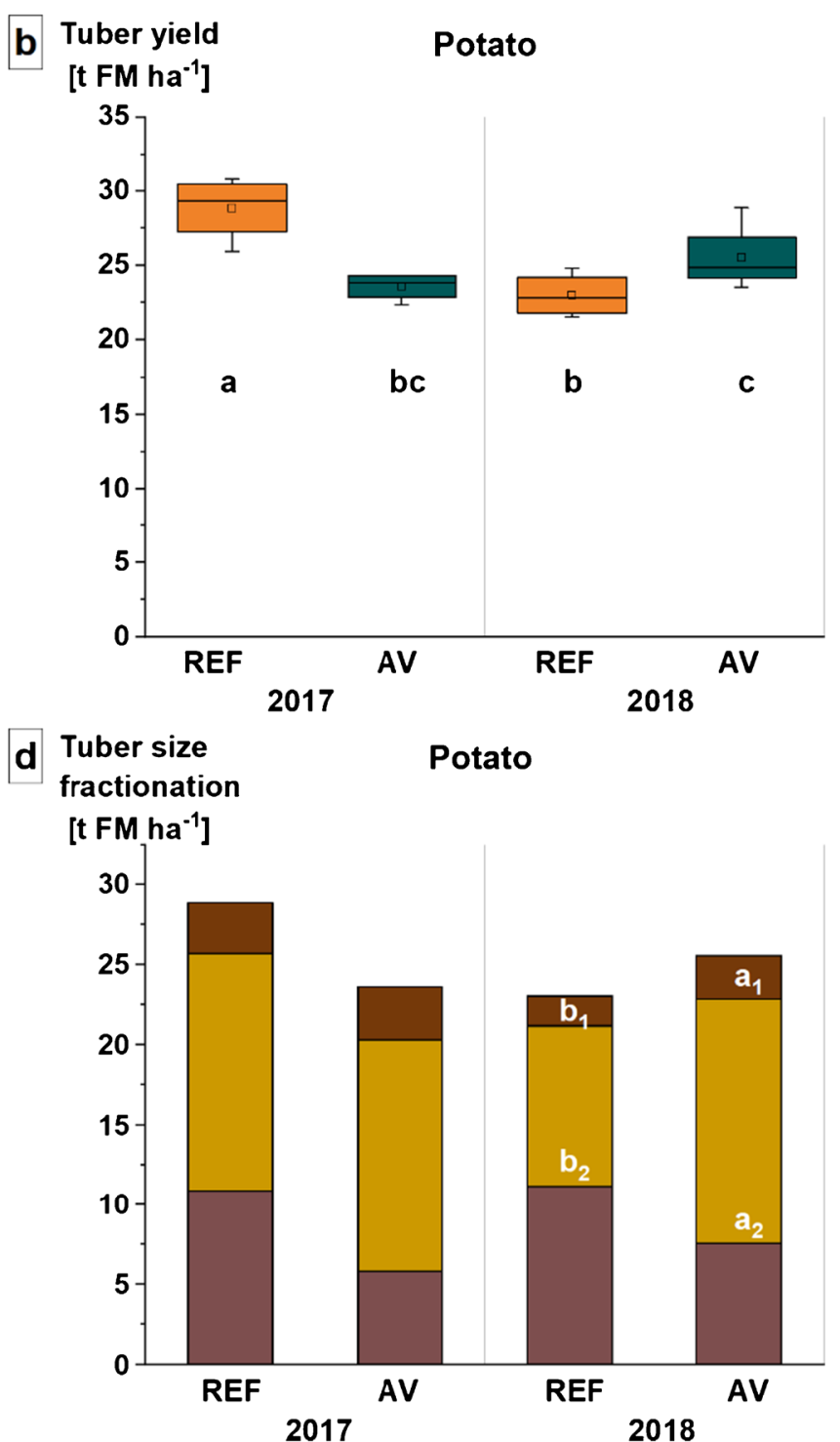

interquartile range, mean (square) and median (center dash). Stacked bars in (c) represent grass-clover cuts $\left(1^{\text {st }}\right.$ cut down to $4^{\text {th }}$ cut top), and in (d) tuber size fractions: diameter $>50 \mathrm{~mm}$ (bottom), $35-50 \mathrm{~mm}$ (middle), $<35 \mathrm{~mm}$ (top).

the share of medium-sized tubers $(35-50 \mathrm{~mm})$ was increased under AV in 2018 ( $p=0.0031)$ (Fig. 5d). In both years, the share of small-sized tubers $(<35 \mathrm{~mm})$ slightly increased under AV $(p>$ 0.05). A recent study by Schulz et al. (2019) investigated the effect of three different shading levels $(12 \%, 26 \%$ and $50 \%)$ on the growth, yield and quality of potatoes in south-west Germany over a 3-year cultivation period (2015-2017). In accordance with our findings, the highest share of undersized potato tubers was found under $26 \%$ shading, while the highest share of oversized tuber was found under full sun conditions (Schulz et al. 2019). These results are of relevance as potato tuber size fractionation is important for the marketing of table potatoes, with small and large-sized tubers being regarded as less marketable. Assuming 
only medium-sized potato tubers $(35-50 \mathrm{~mm})$ are considered marketable, a higher share of tubers was marketable under AV in 2018 in our trial, whereas in 2017 the treatments did not differ significantly. Also, Schulz et al. (2019) found the highest share of marketable tubers under $50 \%$ shading. In experiments performed in New South Wales, Australia, shade application of $21 \%$ and $38 \%$ led to tuber yield reductions ranging from 9 to $27 \%$ (for $21 \%$ shade), and from 23 to $42 \%$ (for $38 \%$ shade), depending on year and irrigation treatment (Sale 1973). Both tuber number and weight were reduced by shading. Although these parameters were not assessed in our experiment, the smaller proportion of large tubers $(>50 \mathrm{~mm}$ ) under $\mathrm{AV}$ indicates that average tuber weight was reduced, too. In the study by Schulz et al. (2019), none of the shading treatments led to significant dry matter (DM) tuber yield reductions in 2015, while in 2017 only the 50\% shading treatment led to significant reductions (Schulz et al. 2019). In 2016, both the $26 \%$ and $50 \%$ shading treatments led to significant yield reductions in comparison with the full-sun control (Schulz et al. 2019). As they hypothesize, the main criterion for achieving sufficient tuber yields is reaching of the light saturation point of potatoes under given climatic conditions. Therefore, not only the level of shading but also yearly variations in solar irradiance and the latitude of the cultivation region need to be considered (Schulz et al. 2019). In contrast to Schulz et al. (2019), who did not find significant yield reductions under $26 \%$ shading, potato tuber yields in our trial were significantly reduced under AV in 2017. This may be explained by several factors like different potato varieties and altered microclimatic conditions, as the field experiment by Schulz et al. (2019) has been performed under irrigated conditions in the Rhine plain. In our trial, lower tuber yields in 2018 than in 2017 may be explained by low precipitation and high temperatures during summer 2018 (also see Sect. 3.1). Both drought and high temperatures are known to be negatively correlated with potato tuber yields (van Loon 1981).

As shown in Sect. 3.1, both air and soil temperature were significantly lower under AV in both years. We therefore hypothesize that, especially in the hot summer of 2018, lower air and soil temperatures under AV may have reduced plant stress, leading to higher tuber yields at harvest compared to the REF site. This is supported by findings of Midmore (1984), who found potato tuber yields to be positively affected by reduced soil temperatures under hot climatic conditions.

In grass-clover, cumulated annual yields of four cuts (DM) were slightly lower under AV: $6.6 \mathrm{tha}^{-1}$ compared to $7.0 \mathrm{t} \mathrm{ha}^{-1}$ in REF in $2017(-5.3 \% ; p=0.23)$, and $5.6 \mathrm{t} \mathrm{ha}^{-1}$ compared to 6.1 $\mathrm{t} \mathrm{ha}^{-1}$ in REF in $2018(-7.8 \% ; p=0.13)$ (Fig. 5c). However, these differences were not significant. While harvestable yields on DM basis were reduced by AV, FM yields were higher: $40 \mathrm{t}$ $\mathrm{ha}^{-1}$ (REF $\left.35.7 \mathrm{t} \mathrm{ha}^{-1}\right)$ in $2017(+12 \% ; p=0.03)$ and $22.7 \mathrm{t} \mathrm{ha}^{-1}$ (REF $22.1 \mathrm{t} \mathrm{ha}^{-1}$ ) in $2018(+2.5 \%$; $p=0.75)$. These findings can be explained by the significantly higher DM content $(p<0.0001)$ of $19.5 \%$ (2017) and $28.7 \%$ (2018) in REF compared to $16.5 \%$
(2017) and 25.3\% (2018) under AV. Ergon et al. (2016) have shown that, in grass/legume mixtures, grasses contribute proportionally more dry matter to the yield than clover, and therefore, our findings can be explained by the higher proportion of grasses in the REF plots (see also Sect. 3.2). As discussed in Sect. 3.2, the cultivation in the partial shade of the AV facility may favor shade-adapted species such as clover. This is in agreement with Pang et al. (2017), who found different forage grass and legume species to be unaffected by shading. Biomass yields of some of the species also used in our study, like Poa pratensis, Trifolium pratense and Trifolium repens, increased by up to $45 \%$ shading (Pang et al. 2017). In addition, DM production of grasses was found to be reduced by shade (Abraham et al. 2014). Apart from cumulated yields, also differences within the different cuts were found between the treatments: In both years, DM yield of the second grass-clover cut was significantly lower under AV. In 2018, DM yield of the fourth cut was significantly higher under AV. For all other cuts, no significant differences were found between the two treatments. However, in both years, DM yields in REF tended to be higher at the first two cuts and lower at the last two cuts, which can also be explained by the different species proportions in the two treatments. In grassland mixtures, grasses are known to produce more dry matter at the beginning of the year, while legumes are higher yielding at the end of the growing season (Ergon et al. 2016). These findings also need to be considered in terms of fodder quality, as higher protein and lower fiber contents can be expected as a result of higher shares of clover. In 2018, the proportion of clover did not become higher under AV until the end of the season. This may be due to dry weather conditions as well as a generally lower proportion of clover in the second year of the grass-clover mixture as a consequence of increased nitrogen levels (Ergon et al. 2016).

The results showed for the first time that harvestable yields of winter wheat, potatoes and grass-clover were significantly affected by AV. On a 2-year average, harvestable yields under AV decreased by about $6.5 \%$ (grass-clover), $7.2 \%$ (potato) and $8 \%$ (winter wheat). The results are comparable to the average yield reduction of $7.1 \%$ found in celeriac within the 2-year field trial (Weselek et al. 2021). Besides crop yield reductions, also a certain loss of cultivation area through the inaccessible areas between the stilts of the AV facility has to be taken into consideration. Its extent depends on whether the field is managed in a lengthwise or crosswise direction to the facility and also how the working widths of the machinery fit the distance between the stilts. In our field trial, the field was managed in a crosswise direction. In 2017, the mean width of the inaccessible strips between the different cultivation area segments was estimated and resulted in a total area loss of approximately $8.3 \%$, which has to be considered in terms of crop yield reductions. Taking into account that at the same time, $246 \mathrm{MWh}$ energy have been produced by the AV facility only in the first cropping year, leading to an improved land use of $56-86 \%$ (Trommsdorff et al. 2021), such reductions in agricultural yields seem to be 
tenable. In contrast to the REF site, harvestable yields of winter wheat and potatoes cultivated under AV were stable in both years. This supports findings of Amaducci et al. (2018) that in the long term, AV may have yield-stabilizing effects in nonirrigated systems: maximum yields are lower than for open field production in years with favorable weather conditions, but this is compensated by lower yield losses in less optimal years. However, to assess potential yield stabilizing effects of AV, further trial years are necessary. As indicated by the results of 2018 , under dry conditions with high solar irradiance, beneficial effects of shading - either directly or indirectly through reduced soil temperatures - on crop productivity are possible. This has recently been confirmed by Barron-Gafford et al. (2019), who found chiltepin pepper and tomato production to be positively affected by the cultivation underneath an AV system under dryland conditions in Arizona, USA. However, the study does not provide sufficient data to assess the impacts on fruit yields, as only fruit number is presented, while information on fruit weights and marketable yields is missing. In addition, Barron-Gafford et al. (2019) found that water retention after irrigation was improved by AV, further emphasizing potential synergistic effects of AV on crop production in arid climates. Besides different climatic conditions in 2017 and 2018, effects of crop rotation also need to be considered in our trial, when comparing both years (Table 1). In 2017, the preceding crop of all treatments in the experiment was perennial grass-clover, which covered the study site for 3 years during the construction of the AV facility. Besides the impact of AV on crop development and yields, future research should also take crop quality into account. In celeriac, first results showed that chemical composition was only barely affected by AV (Weselek et al. 2021), but further studies are needed. As shown for winter wheat, the cultivation under AV led to decreased thousand grain weight as well as to a shift in grain size distribution. It can be assumed that this will also affect grain composition with an increased bran fraction and consequently altered chemical composition and flour yields. As crop quality is one of the most important factors in terms of marketing, potential effects of AV on quality parameters have to be regarded to fully assess its impact on crop production.

\section{Conclusion}

In this first comprehensive experiment on the effects of AV on crop production of winter wheat, potatoes and grass-clover, it has been shown that both crop development and harvestable yields have been affected by altered microclimatic conditions underneath AV. Measurements of canopy height and leaf area index have shown that shading led to increased growth of aboveground biomass of all investigated crop species, which can be considered as shade-adaptive strategy. However, these findings were not always accompanied by an increased dry matter production of aboveground biomass. While in 2017 all crops were negatively affected by AV with yield losses between -5 to $-20 \%$, winter wheat and potatoes grown under AV benefited in the hot and dry summer of 2018 in comparison to the cultivation under open field conditions. In agreement with other studies, the results indicate that the highest potential of AV systems can be seen in hot and dry climates, where beneficial impacts on crop production are likely. As AV systems are intended to be co-productive systems with dual use purposes for simultaneous energy and agricultural crop production, agricultural yields should not be considered in isolation but together with energy yields as well as potential benefits on land productivity, to evaluate AV systematically. However, this also arises the question, to what extent reductions in agricultural yields will be acceptable. This is in particular the case in temperate climates, where the adverse effects of AV on crop production will probably prevail, as well as in regions with limited cropland, where the preservation of agricultural productivity should be premised, to avoid the loss of agricultural land and further trade-off between food and energy production. Nevertheless, the results in 2018 have shown that AV can become advantageous for crop production even in temperate climates, in order to compensate for the prospective risk of more intensive drought periods as expected due to climate change.

Acknowledgements The authors are grateful to Florian Reyer and his colleagues for managing the field experiment, Moritz Krug for assistance with data loggers and rain gauges, Moritz von Cossel and Ulrich Thumm for help with soil sampling and Dagmar Mezger for support with the analyses of soil samples. Particular thanks to Nicole Gaudet for revising the manuscript and to all scientific and practical partners within the APVRESOLA project: Stephan Schindele and Maximilian Trommsdorff of Fraunhofer Institute for Solar Energy Systems ISE, BayWa r.e., EWS Schönau and the Institute for Technology Assessment and Systems Analysis (ITAS) of Karlsruhe Institute of Technology (KIT).

Authors' contributions Conceptualization, P.H., S.Z. and I.L.; Investigation, A.W. and A.B.; Formal analysis, A.W. and J.H.; Visualization, A.W.; Writing - original draft, A.W. Writing-review \& editing, A.W., A.B., J.H., S.Z., I.L., P.H.; Supervision, P.H. and I.L. All authors read and approved the final manuscript.

Funding Open Access funding enabled and organized by Projekt DEAL. This work was carried out within the APV-RESOLA project which received funding from the German Federal Ministry for Education and Research (BMBF) under grant no. 033L098G. In addition, the corresponding author was supported by a state graduate scholarship received from the Ministry of Science, Research and Arts (MWK) BadenWürttemberg.

Data availability The datasets generated during and/or analyzed during the current study are available from the corresponding author on reasonable request.

\section{Declarations}

Ethics approval Not applicable. 
Conflict of interest The authors declare no competing interests.

Financial interests The authors declare they have no financial interests.

Open Access This article is licensed under a Creative Commons Attribution 4.0 International License, which permits use, sharing, adaptation, distribution and reproduction in any medium or format, as long as you give appropriate credit to the original author(s) and the source, provide a link to the Creative Commons licence, and indicate if changes were made. The images or other third party material in this article are included in the article's Creative Commons licence, unless indicated otherwise in a credit line to the material. If material is not included in the article's Creative Commons licence and your intended use is not permitted by statutory regulation or exceeds the permitted use, you will need to obtain permission directly from the copyright holder. To view a copy of this licence, visit http://creativecommons.org/licenses/by/4.0/.

\section{References}

Abraham EM, Kyriazopoulos AP, Parissi ZM, Kostopoulou P, Karatassiou M, Anjalanidou K, Katsouta C (2014) Growth, dry matter production, phenotypic plasticity, and nutritive value of three natural populations of Dactylis glomerata L. under various shading treatments. Agrofor Syst 88:287-299

Amaducci S, Yin X, Colauzzi M (2018) Agrivoltaic systems to optimise land use for electric energy production. Appl Energy 220:545-561. https://doi.org/10.1016/j.apenergy.2018.03.081

Artru S, Garré S, Dupraz C, Hiel M-P, Blitz-Frayret C, Lassois L (2017) Impact of spatio-temporal shade dynamics on wheat growth and yield, perspectives for temperate agroforestry. Eur J Agron 82:60 70. https://doi.org/10.1016/j.eja.2016.10.004

Barron-Gafford GA, Pavao-Zuckerman MA, Minor RL, Sutter LF, Barnett-Moreno I, Blackett DT, Thompson M, Dimond K, Gerlak AK, Nabhan GP, Macknick JE (2019) Agrivoltaics provide mutual benefits across the food-energy-water nexus in drylands. Nat Sustain 2:848-855. https://doi.org/10.1038/s41893-019-0364-5

Dinesh H, Pearce JM (2016) The potential of agrivoltaic systems. Renew Sust Energ Rev 54:299-308. https://doi.org/10.1016/j.rser.2015.10. 024

Dufour L, Metay A, Talbot G, Dupraz C (2013) Assessing light competition for cereal production in temperate agroforestry systems using experimentation and crop modelling. J Agron Crop Sci 199:217227. https://doi.org/10.1111/jac.12008

Dupraz C, Marrou H, Talbot G, Dufour L, Nogier A, Ferard Y (2011) Combining solar photovoltaic panels and food crops for optimising land use: towards new agrivoltaic schemes. Renew Energy 36: 2725-2732. https://doi.org/10.1016/j.renene.2011.03.005

Elamri Y, Cheviron B, Mange A, Dejean C, Liron F, Belaud G (2018) Rain concentration and sheltering effect of solar panels on cultivated plots. Hydrol Earth Syst Sci 22:1285-1298. https://doi.org/10.5194/ hess-22-1285-2018

Ergon A, Kirwan L, Bleken MA, Skjelvåg AO, Collins RP, Rognli OA (2016) Species interactions in a grassland mixture under low nitrogen fertilization and two cutting frequencies: 1. dry-matter yield and dynamics of species composition. Grass Forage Sci 71:667-682. https://doi.org/10.1111/gfs.12250
Fischer RA (1985) Number of kernels in wheat crops and the influence of solar radiation and temperature. J Agric Sci 105:447-461. https:// doi.org/10.1017/S0021859600056495

Homma M, Doi T, Yoshida Y (2016) A field experiment and the simulation on agrivoltaic-systems regarding to rice in a paddy field. Journal of Japan Society of Energy and Resources 37:23-31. https://doi.org/10.24778/jjser.37.6_23

Kuruppuarachchi DSP (1990) Intercropped potato (Solanum spp. ): effect of shade on growth and tuber yield in the northwestern regosol belt of Sri Lanka. Field Crop Res 25:61-72. https://doi.org/10.1016/ 0378-4290(90)90072-J

Li H, Jiang D, Wollenweber B, Dai T, Cao W (2010) Effects of shading on morphology, physiology and grain yield of winter wheat. Eur J Agron 33:267-275. https://doi.org/10.1016/j.eja.2010.07.002

Majumdar D, Pasqualetti MJ (2018) Dual use of agricultural land: introducing 'agrivoltaics' in Phoenix Metropolitan Statistical Area, USA. Landsc Urban Plan 170:150-168. https://doi.org/10.1016/j. landurbplan.2017.10.011

Marrou H, Dufour L, Wery J (2013a) How does a shelter of solar panels influence water flows in a soil-crop system? Eur J Agron 50:38-51. https://doi.org/10.1016/j.eja.2013.05.004

Marrou H, Guilioni L, Dufour L, Dupraz C, Wery J (2013b) Microclimate under agrivoltaic systems: is crop growth rate affected in the partial shade of solar panels? Agric For Meteorol 177:117-132. https://doi. org/10.1016/j.agrformet.2013.04.012

Marrou H, Wery J, Dufour L, Dupraz C (2013c) Productivity and radiation use efficiency of lettuces grown in the partial shade of photovoltaic panels. Eur J Agron 44:54-66. https://doi.org/10.1016/j.eja. 2012.08 .003

McMaster GS, Morgan JA, Willis WO (1987) Effects of shading on winter wheat yield, spike characteristics, and carbohydrate allocation1. Crop Sci 27:967-973. https://doi.org/10.2135/cropsci1987. 0011183X002700050030x

Midmore DJ (1984) Potato (Solanum spp.) in the hot tropics I. Soil temperature effects on emergence, plant development and yield. Field Crop Res 8:255-271. https://doi.org/10.1016/0378-4290(84) 90073-X

Midmore DJ, Berrios D, Roca J (1988) Potato (Solanum spp.) in the hot tropics V. Intercropping with maize and the influence of shade on tuber yields. Field Crop Res 18:159-176. https://doi.org/10.1016/ 0378-4290(88)90006-8

Pang K, van Sambeek JW, Navarrete-Tindall NE, Lin C-H, Jose S, Garrett HE (2017) Responses of legumes and grasses to non-, moderate, and dense shade in Missouri, USA. I. Forage yield and its species-level plasticity. Agrofor Syst 88:287. https://doi.org/10. 1007/s10457-017-0067-8

Sale PJM (1973) Productivity of vegetable crops in a region of high solar input II. *Yields and efficiencies of water use and energy. Aust $\mathrm{J}$ Agric Res 24:751-762. https://doi.org/10.1071/AR9730751

Schindele S, Trommsdorff M, Schlaak A, Obergfell T, Bopp G, Reise C, Braun C, Weselek A, Bauerle A, Högy P, Goetzberger A, Weber E (2020) Implementation of agrophotovoltaics: techno-economic analysis of the price-performance ratio and its policy implications. Appl Energy 265:114737. https://doi.org/10.1016/j.apenergy.2020. 114737

Schulz VS, Munz S, Stolzenburg K, Hartung J, Weisenburger S, GraeffHönninger S (2019) Impact of different shading levels on growth, yield and quality of potato (Solanum tuberosum L.). Agronomy 9: 330. https://doi.org/10.3390/agronomy 9060330 
Sekiyama T, Nagashima A (2019) Solar sharing for both food and clean energy production: performance of agrivoltaic systems for corn, a typical shade-intolerant crop. Environments 6:65. https://doi.org/10. 3390/environments6060065

Trommsdorff M, Kang J, Reise C, Schindele S, Bopp G, Ehmann A, Weselek A, Högy P, Obergfell T (2021) Combining food and energy production: design of an agrivoltaic system applied in arable and vegetable farming in Germany. Renew Sust Energ Rev 140:110694. https://doi.org/10.1016/j.rser.2020.110694

van Loon CD (1981) The effect of water stress on potato growth, development, and yield. Am Potato J 58:51-69. https://doi.org/10.1007/ BF02855380
Weselek A, Ehmann A, Zikeli S, Lewandowski I, Schindele S, Högy P (2019) Agrophotovoltaic systems: applications, challenges, and opportunities A reviews. Agron Sustain Dev 39:35. https://doi.org/10. 1007/s13593-019-0581-3

Weselek A, Bauerle A, Zikeli S, Lewandowski I, Högy P (2021) Effects on crop development, yields and chemical composition of celeriac (Apium graveolens L. var. rapaceum) cultivated underneath an agrivoltaic system. Agronomy 11:733. https://doi.org/10.3390/ agronomy 11040733

Publisher's note Springer Nature remains neutral with regard to jurisdictional claims in published maps and institutional affiliations. 